Thorax (1973), 28, 273.

\title{
Ultrastructure of the cardiac myxoma and the papillary tumour of heart valves
}

\author{
P. G. I. STOVIN, DONALD HEATH, and S. U. KHALIQ \\ The Sims Woodhead Memorial Laboratory, Papworth Hospital, Papworth Everard, Cambridge and \\ The Department of Pathology, University of Liverpool
}

\begin{abstract}
The ultrastructure of a cardiac myxoma has been studied and compared with that of a 'papillary tumour of heart'. The histochemistry of the myxoma was studied at the same time. The predominant myxoma cell contains intracytoplasmic fibrils similar to those occurring in cells ('myofibroblasts') found in granulation tissue, deep within thrombi, and in the subendocardial layer of the heart. It also contains numerous secretory granules which appear to discharge their contents into the pericellular matrix. The material adjacent to the myxoma cell is shown by histochemistry to contain hyaluronic acid and chondroitin sulphate acidic mucins while the surrounding stroma contains sialomucins. The ultrastructure and histochemistry of the cardiac myxoma are very similar to those of the 'papillary tumour of heart' which is widely regarded as nonneoplastic and formed by growth of a Lambl's excrescence. Hence these findings do not resolve the classical controversy as to whether the cardiac myxoma is neoplastic or thrombotic in origin.
\end{abstract}

There are two types of gelatinous tumour which may occur in the heart. They are strikingly different in their macroscopic appearances, site of development, and clinical importance.

The cardiac myxoma (Fig. 1) is of considerable clinical interest and importance. It may appear either as a semitransparent gelatinous mass which

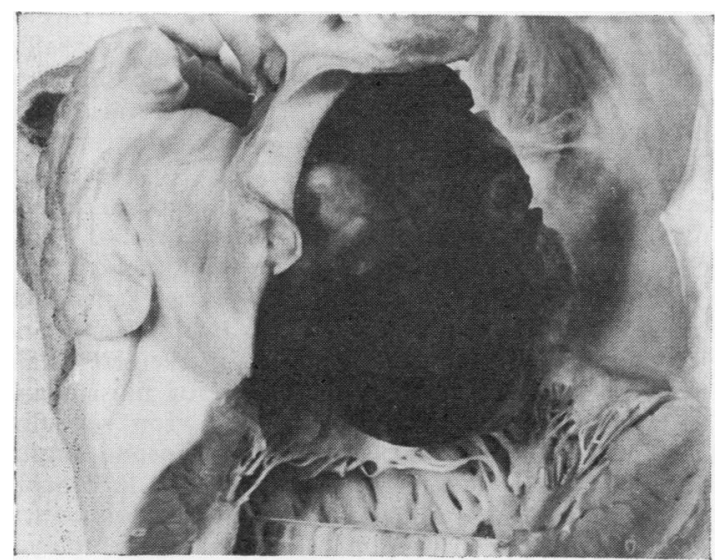

FIG. 1. A myxoma of the left atrium, presenting as a large firm ovoid mass projecting into the mitral valve orifice. is green, pink, or colourless, or as an ovoid firm mass with a pedicle attached to the margin of the fossa ovalis. The myxoma occurs usually in the atria, being three times as common in the left atrium as in the right. It occurs rarely in the ventricles. These gelatinous masses give rise to clinical signs and symptoms in one of four main ways (Heath, 1968). They may obstruct the orifices of the mitral or tricuspid valves. They may give rise to pulmonary arterial hypertension, either by growing in the left atrium and elevating the pressure in that chamber, or by growing in the right atrium and leading to increased pulmonary vascular resistance by multiple embolization of myxoma fragments to the pulmonary arterial tree (Heath and Mackinnon, 1964). Thirdly, the cardiac myxoma may produce a bewildering variety of systemic embolic effects (Goodwin, Kay, and Heath, 1965). Finally, it may produce generalized systemic disturbances such as anaemia and altera. tions in plasma proteins.

On the other hand, the papillary tumour of heart (Fig. 2) is small and usually occurs on one or more of the heart valves, although rarely it may develop on the endocardial surface of a ventricle (Heath and Thompson, 1967). Macroscopically it looks like a sea anemone with multiple fronds which project into the cavity of the heart. This lesion is usually clinically silent, although in one case a papillary tumour led to periodic angina by 


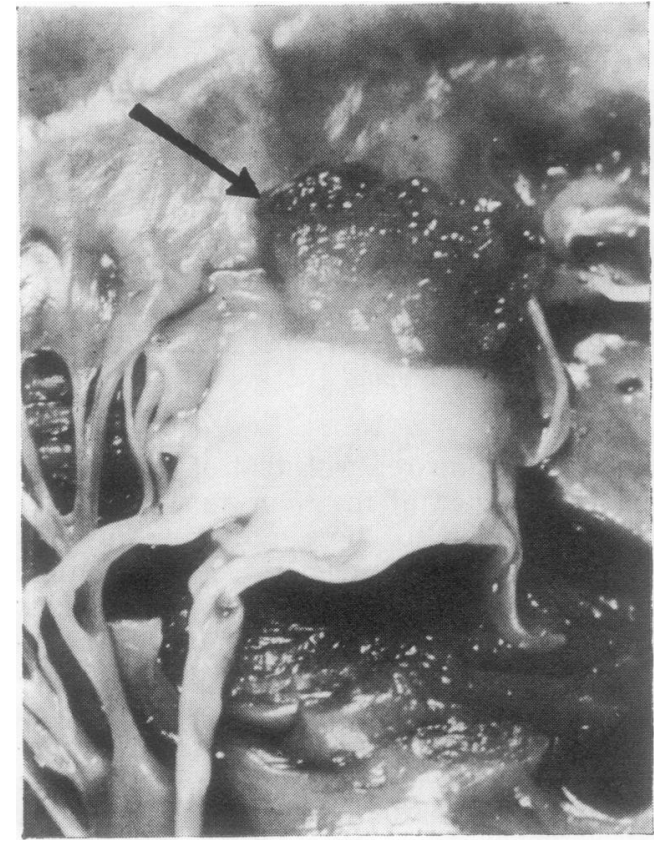

FIG. 2. Papillary tumour of the tricuspid valve, the ultrastructure of which is described in this paper. It is gelatinous and resembles a sea anemone in form. The papillary tumour is indicated by an arrow.

occasional blockage of the ostium of a coronary artery (Heath, Best, and Davis, 1961).

From a pathological standpoint both of these lesions consist of cells of indeterminate origin associated with a matrix of acid mucopolysaccharide. There has been prolonged controversy as to whether these lesions are neoplastic or thrombotic in nature. While most regard the atrial myxoma as a neoplasm there is widespread acceptance of the view of Pomerance (1961) that 'the papillary tumour of heart valves' is not neoplastic but merely a giant Lambl's excrescence. However, the histological appearances of the two lesions are similar except for the fact that in the papillary tumour the cells are largely restricted to a covering over a jelly-like core whereas in the myxoma the cells and matrix are more intimately admixed (Heath, 1968). By light microscopy it is impossible to resolve the controversy of the pathogenesis of the myxoma or to determine the nature of its predominant cell. In this investigation we sought the answer to these two questions by examination of the ultrastructure of the two lesions combined with an investigation of the histochemistry of the myxoma.

\section{CASES STUDIED}

CARDIAC MYXOMA A married woman aged 50 years complained of swelling of the ankles and gradually increasing exertional and nocturnal dyspnoea for five years. She had clinical signs of mitral stenosis is which varied in intensity from time to time. This led $\vec{\circ}$ to her being investigated for the possible presence of a left atrial myxoma. An angiogram showed a filling $\vec{\omega}$ deficiency in the left atrium with partial occlusion of $\sigma$ the right inferior pulmonary vein. The ESR (Wester- $\vec{x}$ gren) was raised at $31 \mathrm{~mm}$ in one hour but serum i electrophoresis showed no abnormality.

At open heart operation (Mr. B. B. Milstein) a $\omega$ myxoma was found to arise by a broad base from the lower half of the atrial septum and adjacent posteromedial wall of the left atrium. This was excised together with the portion of the atrial septum from which it arose. The myxoma was impacted in the mitral orifice, the cusps of the valve being slightly thickened. The atrial septum was repaired with peri- $\overrightarrow{0}$ cardium. The resected myxoma measured $4.3 \times 4.0 \times \omega$ $3.2 \mathrm{~cm}$ and was lobulated and gelatinous. The surface was smooth. In places the myxoma was yellow and in others pink-grey in colour. It was attached by a broad pedicle to an ellipse of muscular atrial septal wall, $4.0 \times 1.8 \mathrm{~cm}$.

PAPILLARY TUMOUR A woman of 60 years died from multiple injuries in which she sustained fractures of the skull and pelvis. At necropsy a papillary tumour, $1 \mathrm{~cm}$ in diameter, was found on the anterior cusp of the tricuspid valve as an incidental finding.

\section{METHODS}

Within 10 minutes of resection small pieces of the myxoma were placed in the following fixatives for subsequent histochemistry: cold formol saline, acetone, formol acetate, Carnoy's fluid, and formol Zenker's solution. The fixed tissue was then paraffin 은 processed and sections were cut at a thickness of $5 \mu \mathrm{m}$ for various staining procedures. Pieces were also fixed o in phosphate buffered $5 \%$ glutaraldehyde for subsequent electron microscopy. Unfixed pieces of $O$ myxoma were also frozen and stored in liquid $N$ nitrogen until subsequently cut on a cryostat at $-20^{\circ}$ 尺 $\mathrm{C}$ for the detection of alkaline phosphatase.

The following staining reactions were carried out, in each case according to the methods of Disbrey and 0 Rack (1970): haematoxylin and eosin, Weigert's stain $\overparen{D}$ for elastin with a van Gieson stain for muscle and $\stackrel{\mathscr{S}}{+}$ collagen, Gordon and Sweet's stain for reticulin, 0 Lendrum's Martius scarlet blue and phosphotungstic $\bar{O}$ acid haematoxylin for fibrin, and periodic acid Schiff $\overrightarrow{\mathbb{D}}$ with and without prior diastase digestion for neutral $\stackrel{?}{\mathbb{Q}}$

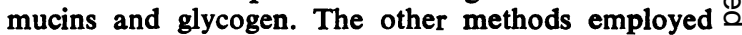
were Gomori's technique for alkaline phosphatase, the alcian blue magnesium chloride method of Scott $O$ and Dorling (1965), the periodate Schiff method of $\frac{O}{0}$ Scott and Dorling (1969) for acid glycosaminoglycans, 
and Todd's (1959) method for fibrinolysin activator.

Tissue for electron microscopy was post-fixed in $1 \%$ aqueous osmium tetroxide, stained with uranyl acetate during dehydration, and embedded in Araldite. Sections $1 \mu \mathrm{m}$ thick were cut with an LKB Ultrotome III microtome, mounted on glass slides, and stained with toluidine blue for light microscopy and for selection of suitable areas for electron microscopy. Thin sections of $50 \mathrm{~nm}$ were cut, mounted on naked copper grids, and stained with lead citrate. The grids were examined with an AEI EM 6B electron microscope with an accelerating voltage of $60 \mathrm{kV}$.

\section{RESULTS}

LIGHT MICROSCOPY AND HISTOCHEMISTRY Cold formol saline and glutaraldehyde proved to be the most suitable fixatives giving rise to the least shrinkage of cells and of the pericellular mucin. Nuclear detail in sections stained with haematoxylin and eosin was sharpest in tissue fixed in Carnoy's fluid, cold formol saline, and acetone. The pericellular pools of mucin and more solid areas of stroma tended to show a brighter and more intense eosinophilia after fixation in Carnoy's fluid or glutaraldehyde. Fixation in Carnoy's fluid or by the formol Zenker technique augmented the effect of increasing the magnesium chloride concentration on the staining with alcian blue.

The myxoma was composed of oval or stellate cells embedded in a loose matrix of acid mucopoly- saccharide. The cells were present either singly or in groups and many of them were surrounded by halos of acid mucopolysaccharide. The stroma contained a few collagen fibres and showed a streaky staining with silver salts, suggesting the presence of reticulin. In ill-defined areas of the stroma there was a diffuse infiltration with fibrin.

The myxoma cells were close to fine capillaries, and larger vessels were found at its base. Ironcontaining macrophages and mast cells were present. The capillaries and some of the myxoma cells in unfixed cryostat sections gave a strong reaction for alkaline phosphatase (Fig. 3) but no fibrinolytic reaction could be demonstrated in them.

Histochemical studies of the stroma of the myxoma were carried out. Sections stained by the Hale's dialysed iron technique showed an intense blue staining of the pericellular halos. There was a less intense and ill-defined patchy reaction in the stroma and in the cell cytoplasm. A similar distribution of reaction was given with the periodate Schiff reaction which was blocked by borohydride. Weak staining of the stroma by alcian blue occurred up to but not above $0.5 \mathrm{M}$ magnesium chloride; the matrix was also weakly PAS positive. In contrast the pericellular halos were PAS negative but stained with alcian blue with concentrations of magnesium chloride up to $0.65 \mathrm{M}$. No intracytoplasmic staining by alcian blue was

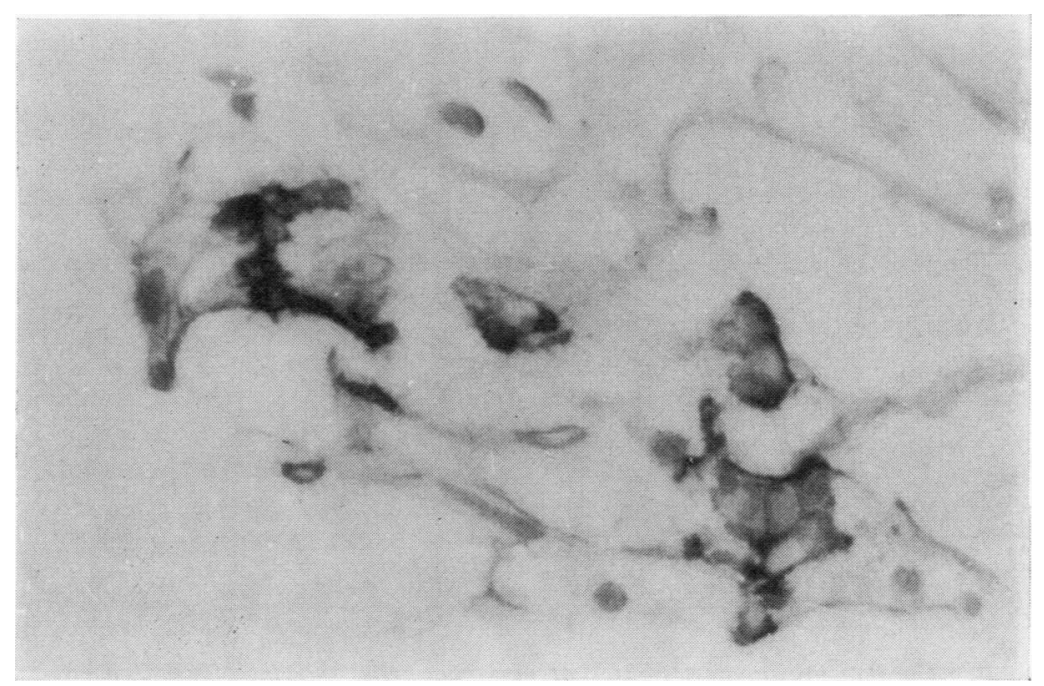

FIG. 3. Cardiac myxoma. Section stained by Gomori's technique to demonstrate alkaline phosphatase in myxoma cells and endothelial cells of associated blood capillaries. $(\times 425)$. 
demonstrable but the myxoma cells gave a variable, mostly strongly positive reaction with PAS which was unaffected by diastase but which was reduced by prior treatment with cetyl pyridinium chloride. Staining with alcian blue was abolished in cryostat sections following incubation in hyalase.

These results are interpreted as indicating that the halos contained hyaluronic acid and chondroitin sulphate acidic mucin while the remainder of the stroma contained some hyaluronic acid and sialomucins. For control material organized but not collagenized thrombus in a surgically resected auricle and in a ventricular aneurysm were studied. These tissues showed the same histochemical reactions, indicating a chondroitin sul- phate in the immature myxofibroblastic areas and sialomucins in the surrounding areas.

Histological examination of the papillary tumour showed it to consist of multiple fronds which consisted of a central fibrous core, a surrounding zone of loose matrix similar to that described above for the myxoma, and a covering of cells. Histochemistry was not carried out but previous studies (Heath, 1968) have shown that it is identical with that of the cardiac myxoma.

ELECTRON MICROSCOPY The atrial myXoma consisted of single cells or groups of them embedded in a matrix composed of granular material and fibres (Fig. 4). The cells in groups were attached to one another by tight junctions (Figs. 4 and 5).

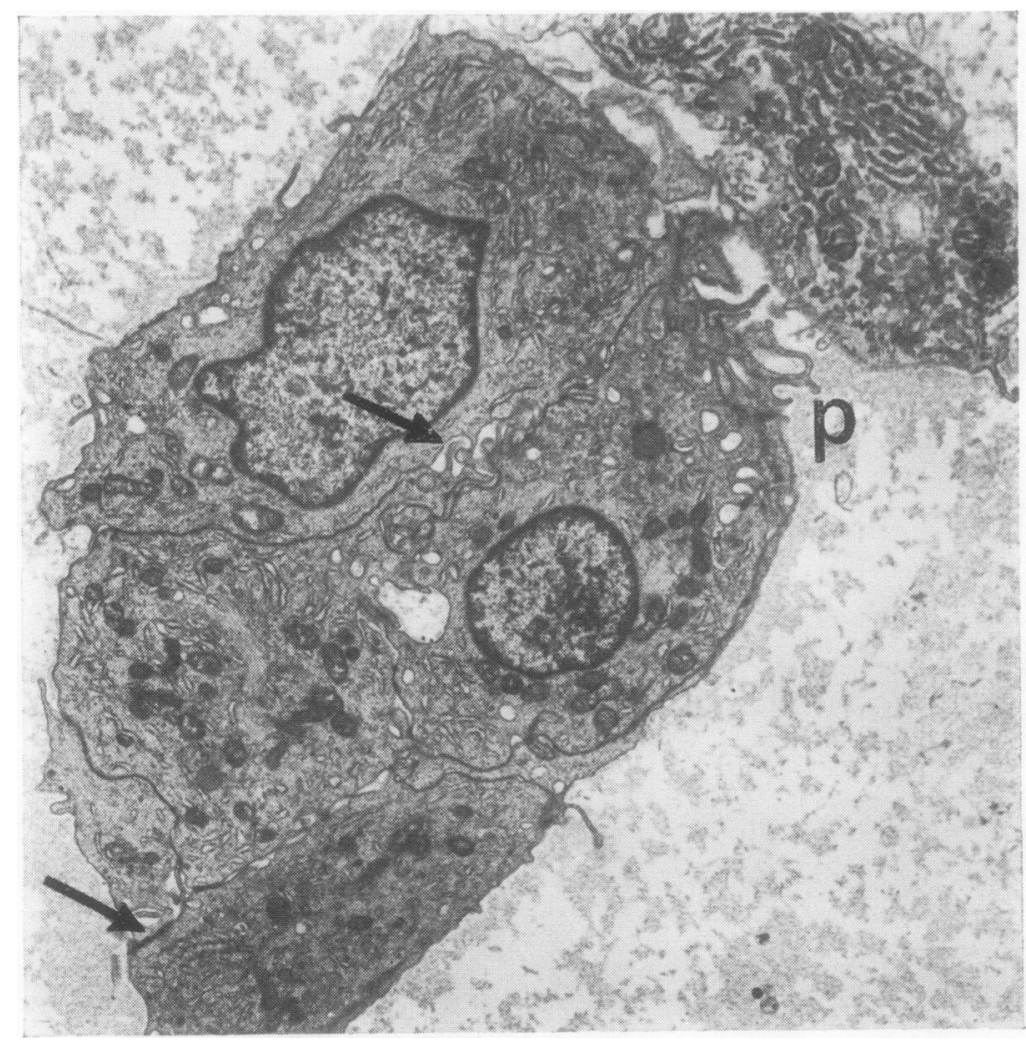

FIG. 4. Cardiac myxoma. A cluster of myxoma cells, showing finger-like processes $(p)$ at the cell border, with surrounding matrix. Some of the processes of the upper two cells interlock (upper arrow). Compare this appearance with that of the 'papillary tumour of heart' shown in Fig. 11. Note the tight junctions (lower arrow). Part of a fibrocyte is also included in the top right-hand corner. $(\times 6,000)$. 


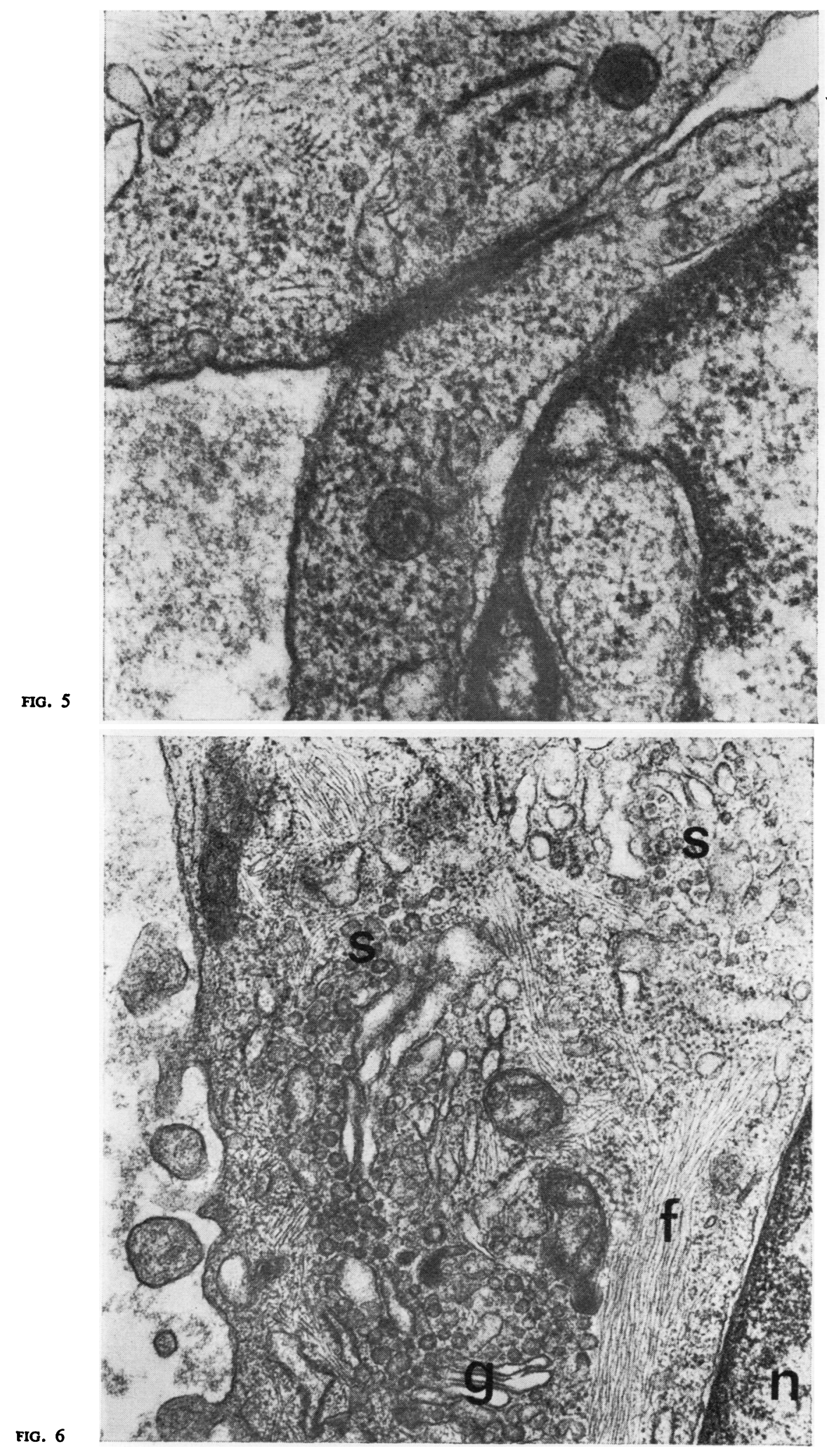

See p. 279

for legends

to Figs.

5-9

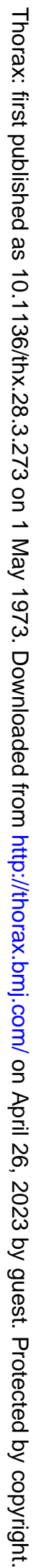




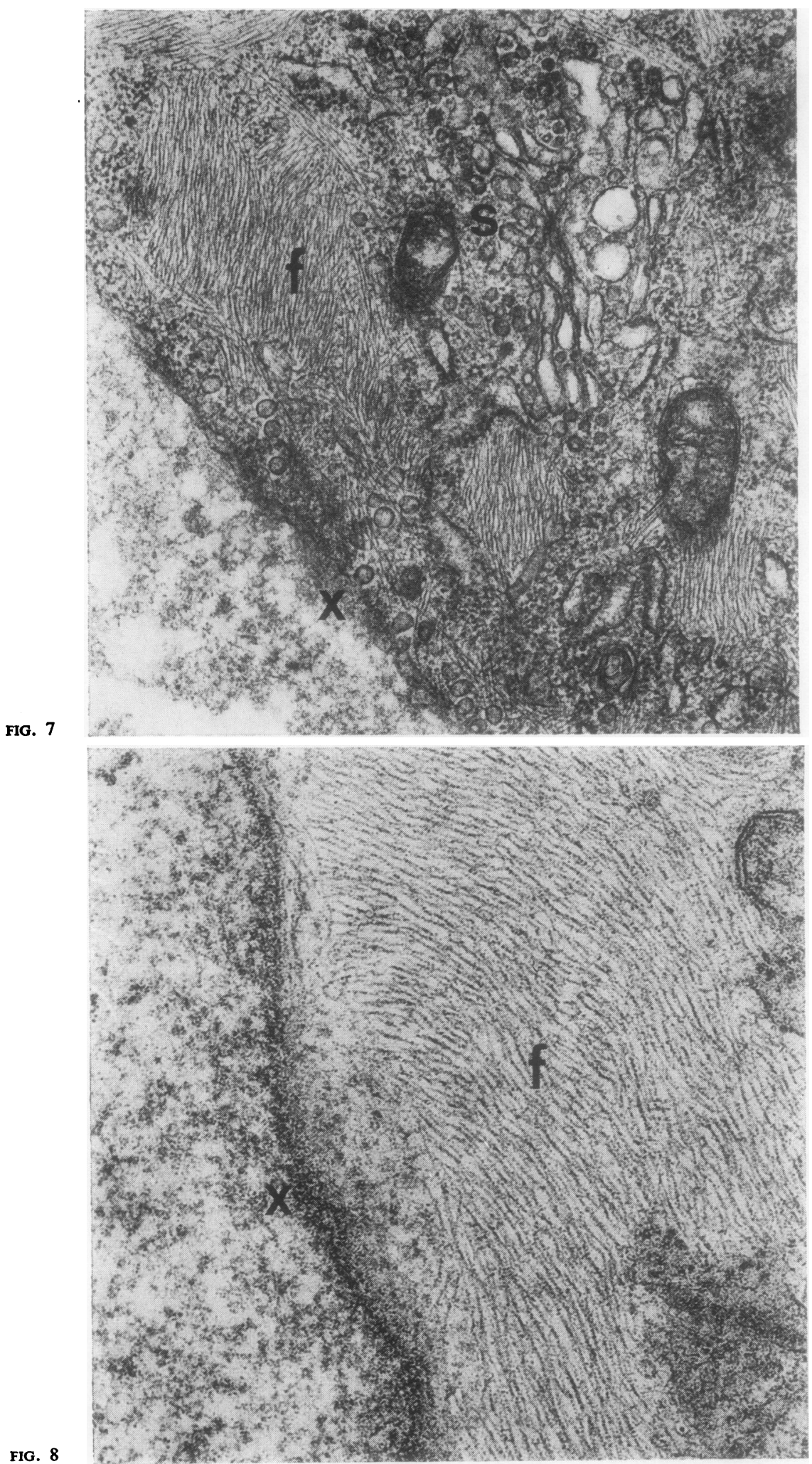


FIG. 9

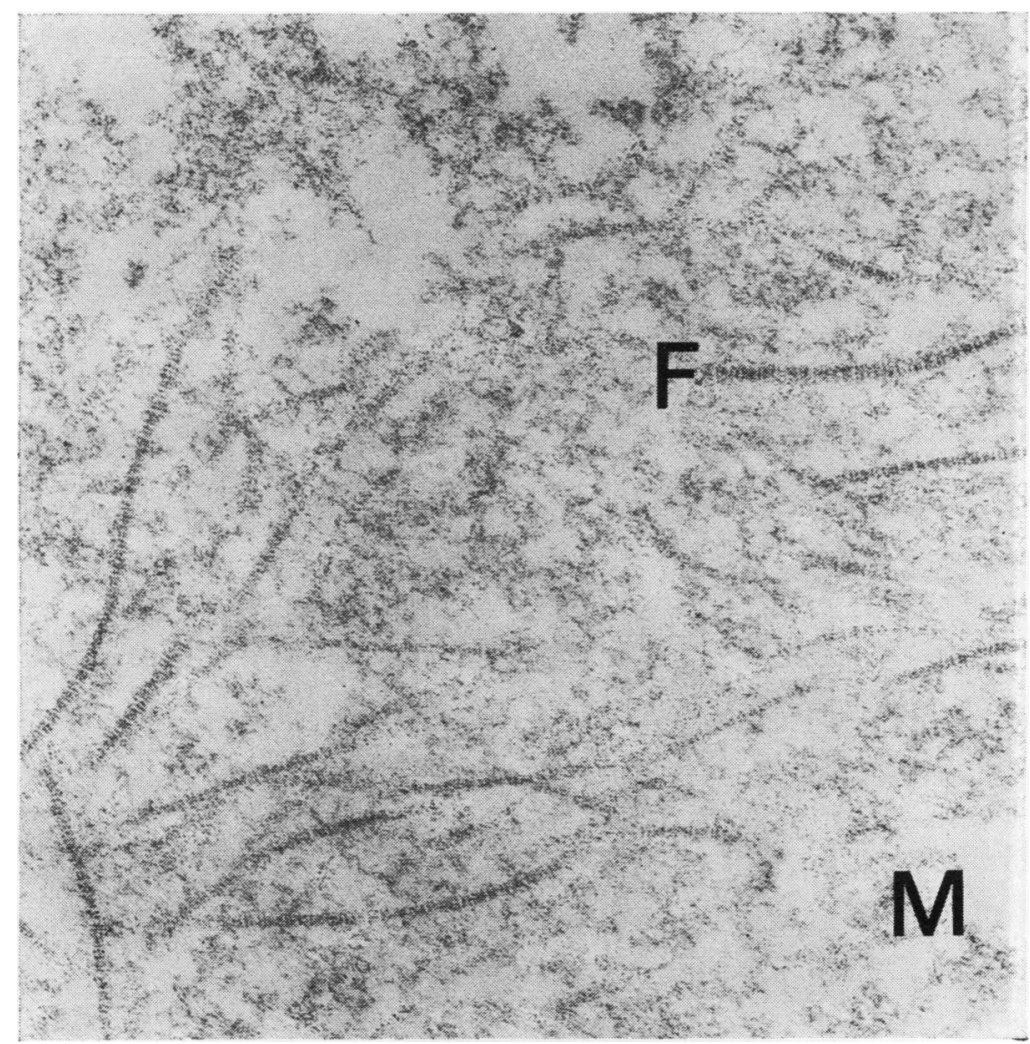

FIG. 5. Cardiac myxoma. A tight junction between two myxoma cells seen at higher magnification. $(\times 60,000)$.

FIG. 6. Cardiac myxoma. Part of a myxoma cell including the edge of the nucleus $(n)$ and showing processes at the cell border. Note the Golgi apparatus $(g)$ and the numerous secretory granules (s) scattered throughout the cytoplasm. Bands of fine fibrils $(f)$ are also seen. $(\times 30,000)$.

FIG. 7. Cardiac myxoma. Part of another myxoma cell showing the secretory granules (s) some of which have fused with the plasma membrane to discharge their contents on to the cell surface $(x)$. Note the bands of fibrils $(f) .(\times 30,000)$.

FIG. 8. Cardiac myxoma. The edge of a myxoma cell at higher magnification showing the fine fibrils $(f)$. There is a layer of granular material on the cell surface $(x)$ which merges into the granular matrix seen to the left of the picture. $(\times 60,000)$.

FIG. 9. Cardiac myxoma. Stroma consisting of fibres (F) embedded in a finely granular matrix $(M) .(\times 60,000)$.

The individual cells were ovoid and some $10 \mu \mathrm{m}$ in diameter. On their borders were long finger-like processes which interdigitated with similar projections from neighbouring cells (Fig. 4). Similar interlocking of cells by cytoplasmic processes was seen in the cells of the papillary tumour (Fig. 11). Occasional fibrocytes were also seen (Fig. 4). The nuclei of the myxoma cells were round or oval and showed peripheral concentrations of chromatin. No mitotic figures were seen.

Within the cytoplasm were many Golgi complexes composed of vesicles and tubules and surrounding them were many secretory globules. Clusters of these globules were seen throughout 


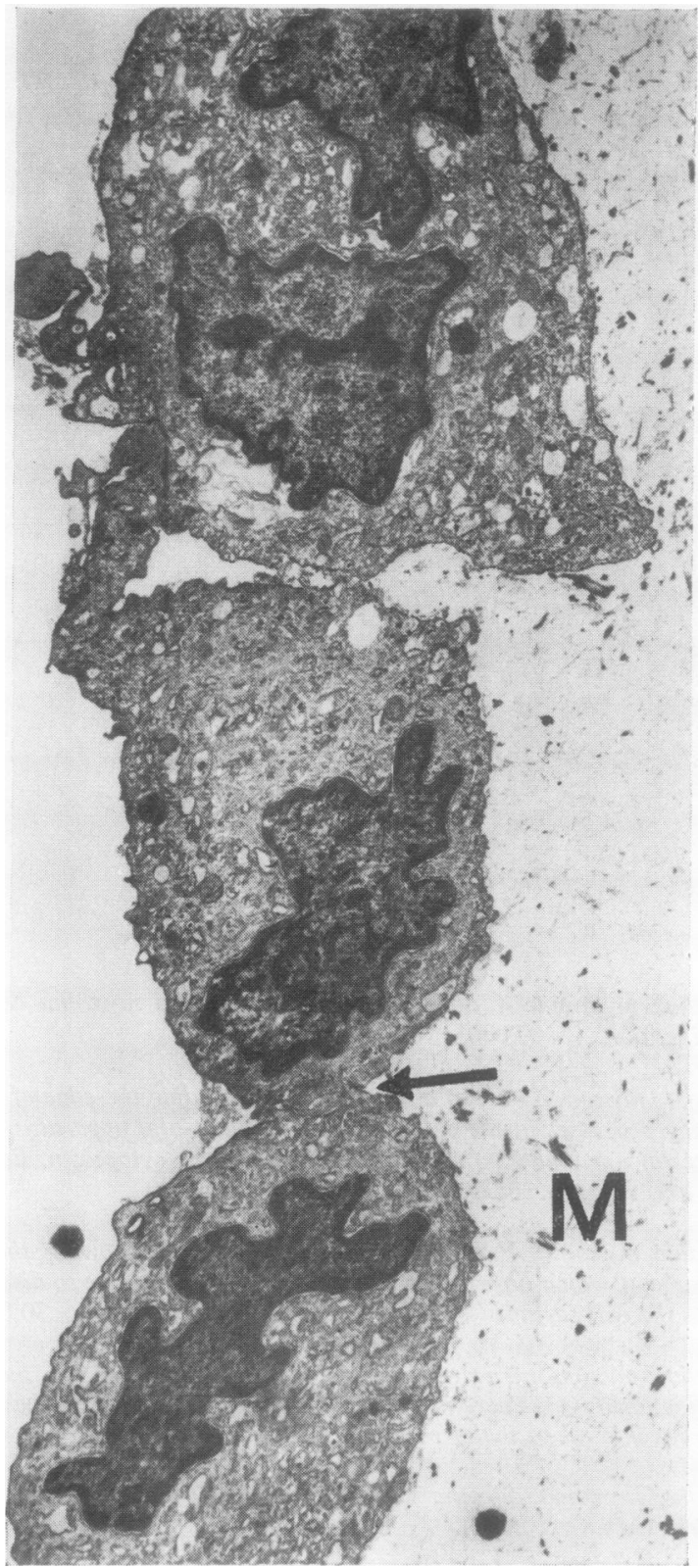

FIG. 10. Papillary tumour of heart valve. Three cells from the cellular covering of the matrix $(M)$ of one of the tumour fronds. The nuclei have a more irregular outline than those of the cardiac myxoma. Note the interlocking of the cells by cytoplasmic processes (arrow). $(\times 6,000)$. 


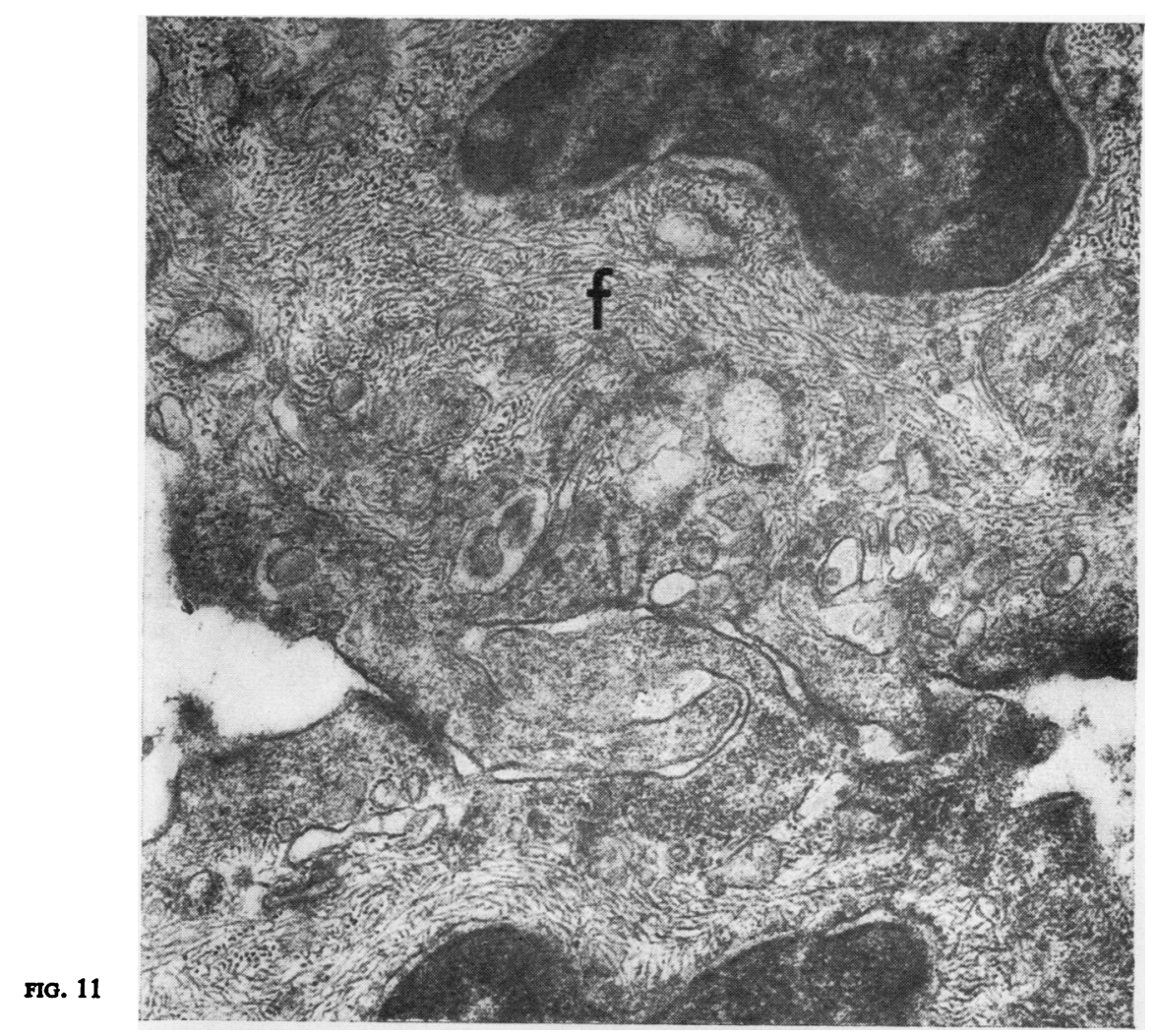

.

See p. 282

for legends to

Figs. 11-13

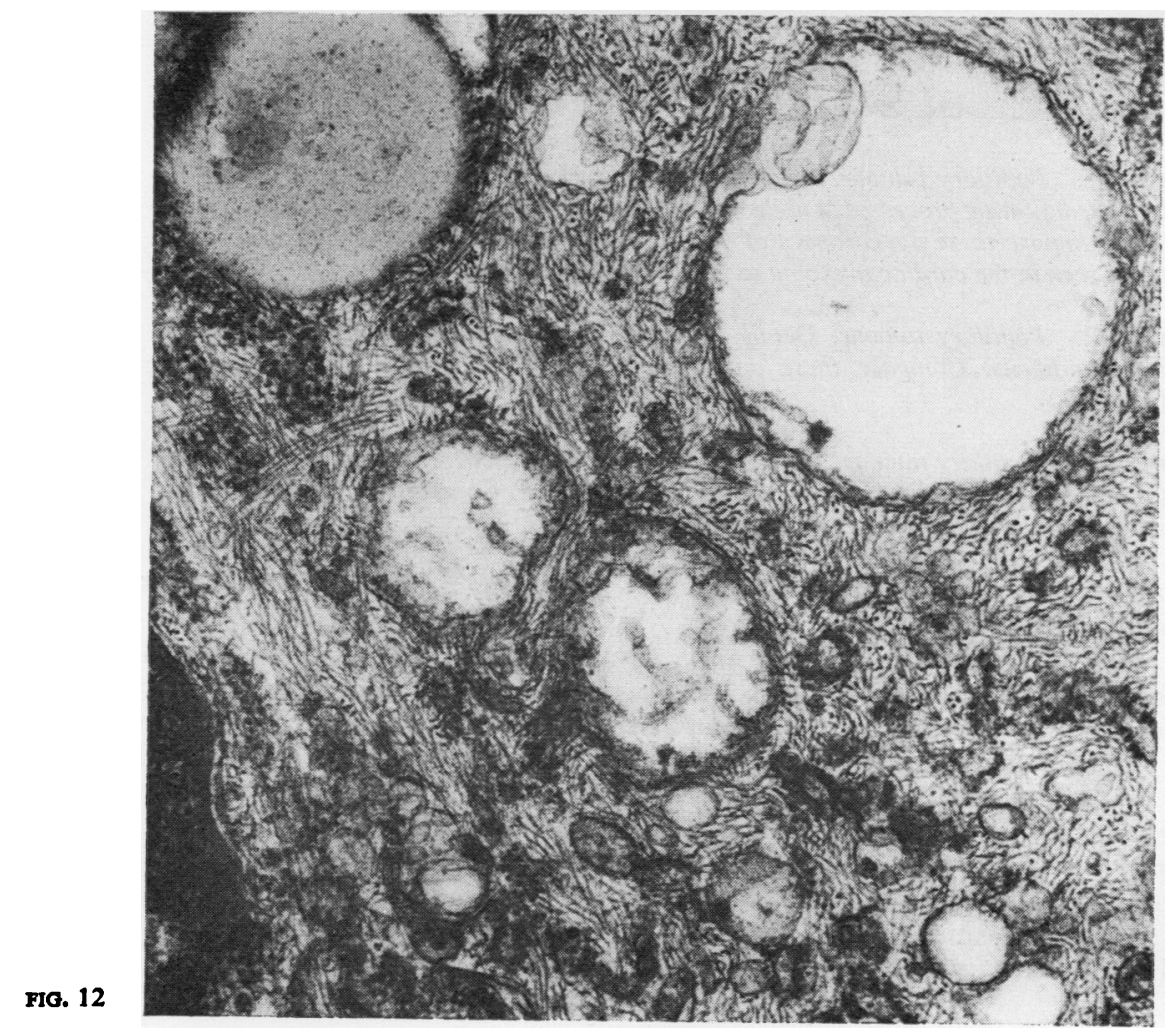




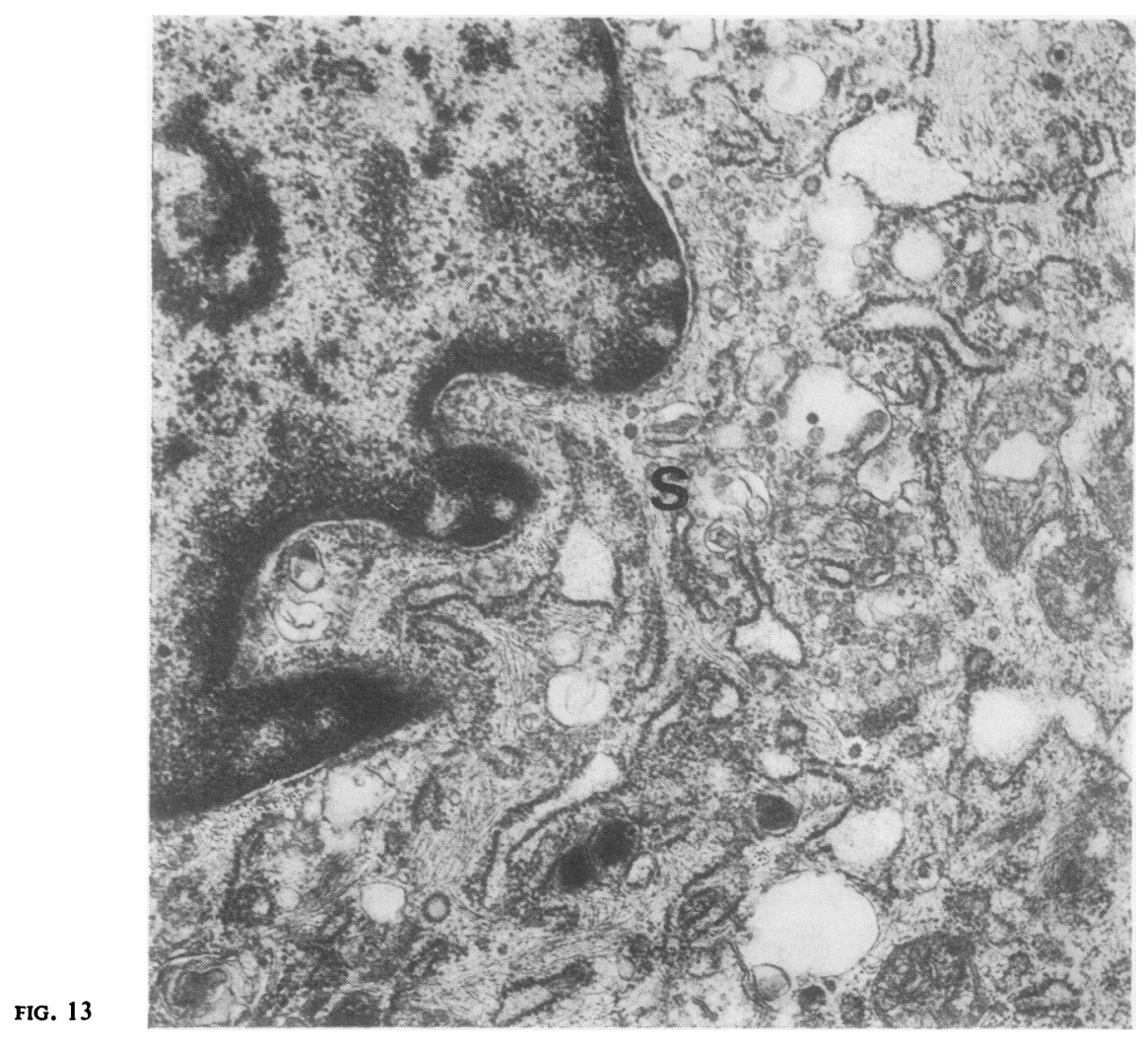

FIG. 11. Papillary tumour. Junction between two cells showing their interlocking by interdigitating processes at higher magnification. Note the intracytoplasmic fibrils (f). Compare these appearances of cell-interlocking in the papillary tumour with those seen in the cardiac myxoma as shown in Fig. $4 .(\times 40,000)$.

FIG. 12. Papillary tumour. Detail of cell to show the feltwork of fine intracytoplasmic fibrils. Compare these appearances with those of the atrial myxoma. $(\times 40,000)$.

FIG. 13. Papillary tumour. Detail of cell to show the numerous secretory granules $(s)$ and the endoplasmic reticulum with wide cisternae. Compare these appearances with those of the atrial myxoma. $(\times 20,000)$.

the areas of cytoplasm not occupied by the bands of fibrils described below (Fig. 6). Some of these were present in the zone subjacent to the cell surface and there was fusion of the walls of some of these intracytoplasmic vesicles with the plasma membrane. The material within the globules was particulate like that of the matrix surrounding the cell and forming a thin layer of particulate secretion clinging to the cell surface. These appearances were interpreted as a discharge of the contents of the intracytoplasmic vesicles derived from the Golgi complexes into the pericellular matrix.
A striking feature of the ultrastructure of the myxoma cells was the presence of fine intracytoplasmic fibrils (Figs. 6 and 7). There were no associated focal condensations as would be anticipated if the fibrils were the myofibrils of smooth muscle cells. The fibrils ran in bands in criss-cross fashion throughout the cytoplasm between the organelles. As a result some ran parallel to the nuclear membrane (Fig. 6) and others were subjacent to the cell surface (Figs. 7 and 8). At high magnification the fibrils appeared to be beaded (Fig. 8).

There was a rough endoplasmic reticulum in the 
cells with wide cisternae containing faintly staining granular material. Free ribosomes were also present. The mitochondria showed no remarkable features.

The matrix surrounding the myxoma cells consisted of a finely granular material, which presumably corresponds to the acid mucopolysaccharide demonstrable on histochemistry and fibres up to $25 \mathrm{~m} \mu$ in diameter (Fig. 9). These fibres show beading but no periodicity suggestive of collagen fibres.

The ultrastructure of the papillary tumour differed from that of the cardiac myxoma in so far as the cells, instead of forming clusters in the matrix, formed a covering over the matrix of the tumour fronds (Fig. 10). In sections this covering appeared as a single row of cells (Fig. 10) which maintained their association by the interlocking of finger-like processes from the cell surface (Fig. 11). Small tight junctions were also visible (Fig. 11). The nuclear outlines were somewhat more irregular than those of the myxoma.

In general, however, the ultrastructure of the cells of the papillary tumour of heart valves is very similar to that of the cardiac myxoma. In particular there were interlacing bundles of fine filaments (Figs. 11 and 12), numerous fine secretory droplets (Fig. 13), and plentiful rough endoplasmic reticulum with wide cisternae (Fig. 13).

\section{DISCUSSION}

The most striking feature of the ultrastructure of the atrial myxoma is the abundance of fine cytoplasmic fibrils similar to those which occur in smooth muscle cells and which are considered to represent their contractile component (Rhodin, 1962). The presence of such filaments led Merkow and his associates (1969) to conclude that the cells of an atrial myxoma should be regarded as what they term a 'myoid type cell'. Certainly such filaments are to be found in the cells of neoplasms derived from smooth muscle such as the glomus tumour (Harris, 1971), although it should be noted that in such unequivocal muscle cells the fine cytoplasmic filaments are associated with focal condensations. There is no doubt that cells with cytoplasmic filaments are to be found commonly in the heart and great vessels. Atrial endocardium, from which cardiac myxomas most frequently arise, contains cells considered to be smooth muscle since they stain brilliantly following the addition of fluorescinated antiserum to human uterine actomyosin or myosin (Becker and Murphy, 1969).
Stein, Mauro, Thibodeau, and Alley (1969) recognized several cell types as occurring in the cardiac myxoma, noting that a clear definition and classification of individual cells could not be made in some cases. They found that the predominant cell type present contained fibrils which they also interpreted as myofilaments and this led them to designate the cells as mature smooth muscle cells. Also present were fibrocytes and endothelial cells. Stein et al. (1969) believed that these cell types constitute what they call 'subendothelial vasoformative reserve cells'. They are of the opinion that as well as giving rise to cardiac myxomas they are to be found in such conditions as the thickened endocardium overlying hypertrophied infundibular muscle in Fallot's tetrad, or in the thickened aortic valve cusps in rheumatic aortic stenosis. They think that these reserve cells can undergo hyperplasia and differentiation into smooth muscle, fibrocytes, and endothelial cells. Subsequently such cells produce their own secretions so that the differentiated cells become associated with a stroma containing acid mucopolysaccharide, collagen or elastin.

It is of interest to note that cells with intracytoplasmic filaments resembling smooth muscle may arise in thrombi. Davies, Ballantine, Robertson, and Woolf (1972) carried out an ultrastructural study of experimentally induced thrombi in the aorta of the pig. After three days the thrombi consisted of an open network of fibrin within which lipid-rich debris of platelet origin was undergoing phagocytosis by macrophages. After 12 days cells unlike macrophages appeared on the surface and deep in the thrombus. The surface cells resembled endothelium but the deep cells showed numerous intracellular filaments and resembled smooth muscle. It seems from this description that these cells are likely to be of the same type as those found in the cardiac myxoma. This suggests that such cells are not confined to the heart but are widespread in the connective tissues of the body.

Also relevant to this discussion appear to be the investigations of Gabbiani and his associates (1972) into the contractile nature of granulation tissue. When an open wound heals, its surface becomes smaller due to an inward movement of the edges; this is the phenomenon of wound contraction. Gabbiani and his co-workers carried out electron microscopic, pharmacological, chemical, and immunological studies on granulation tissue. They found that contracting granulation tissue contains fibroblasts that develop characteristics typical of smooth muscle. Such fibroblasts develop an extensive cytoplasmic fibrillary system similar 
to that which we and other authors referred to above have described in the cells of the cardiac myxoma. They also show cell-to-cell attachments such as are illustrated in Figs. 4 and 5. The nuclei of these cells show complicated folds and indentations indicative of cellular contraction. Such fibroblasts develop other characteristics typical of smooth muscle. Thus they show immunofluorescent labelling of their cytoplasm with human anti-smooth muscle serum. Strips of granulation tissue when tested pharmacologically in vitro behave similarly to smooth muscle. Gabbiani et al. (1972) are of the opinion that under certain conditions fibroblasts can differentiate into a cell type structurally and functionally similar to smooth muscle and that this cell, the 'myofibroblast', plays an important role in connective tissue contraction.

Parry (1970) described the ultrastructure of Wharton's jelly cells in the full-term umbilical cord. He found that these cells contained bundles of fine filaments and thus bore a superficial resemblance to smooth muscle cells. However, on closer study he came to regard these cells as 'somewhat unusual fibroblasts'. It is clear from these studies of Parry (1970) and Gabbiani et al. (1972) that a cell having features of both smooth muscle cells and fibroblasts is to be found commonly in connective tissue. It seems likely to us that on ultrastructural grounds it is this cell type which predominates in the cardiac myxoma. Williams, Jenkins, and Erasmus (1970), however, believe that it is difficult to characterize a particular cell from the type or amount of intracytoplasmic fibrils. They point out that such fibrils and microtubules are common in a large variety of cells including endothelial and embryonic cells. They do not accept that the fibrils are indicative of any particular cell of origin.

Kelly and Bhagwat (1972) listed the ultrastructural features of typical smooth muscle cells, fibroblasts, and endothelial cells and with this background considered the electron microscopy of the cells of a recurrent left atrial myxoma. They concluded that while the myxoma cells had many features of endothelial cells some were more reminiscent of fibrocytes. On these grounds they accepted the view of Stein and his associates (1969) that the myxoma arises from a 'multipotential endocardial reserve cell'.

The present study shows that the ultrastructure of the cells in a 'papillary tumour of heart valves' is similar to that of myxoma cells. As one of us has noted previously (Heath, 1968), the papillary tumour of heart and the cardiac myxoma are similar macroscopically and on light microscopy, the staining reaction of the stroma which is $\underline{0}$ largely composed of acid mucopolysaccharides $\frac{\bar{c}}{\bar{D}}$ being identical. There is now wide acceptance of $\stackrel{\widetilde{\Phi}}{\mathscr{Q}}$ the view of Pomerance (1961) that papillaryo tumours are not true neoplasms but giant Lambl's?

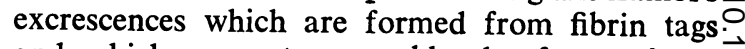
and which come to resemble the form of sea $\vec{\omega}$ anemones by further periodic accretions of fibrin. $\stackrel{\circ}{\circ}$ If one accepts that the papillary tumour is non- $-\vec{x}$ neoplastic, and that it bears a close resemblance $\hat{\infty}_{\infty}$ at ultrastructural level to the cardiac myxoma, one cannot dismiss out of hand the view that the myxoma is also not neoplastic but thrombotic in $\omega$ origin. It is salutary to realize that even with the을 use of an electron microscope this classical prob-lem cannot be resolved.

One obvious distinction between the cardiac myxoma and 'the papillary tumour of the heart' $\overrightarrow{0}$ is that in the former the cells permeate the $\omega$ gelatinous matrix whereas in the latter they are sharply demarcated from the stroma forming a layer one cell thick. Although the cells in the two lesions are ultrastructurally very similar, the difference in their disposition with regard to the $\frac{\Omega}{\mathbb{Q}}$ matrix is perhaps indicative of an important $\stackrel{\varrho}{\vec{D}}$ difference between them not demonstrable by the 을 electron microscope.

In our description of the ultrastructure of the cells of the myxoma and of the papillary tumour of heart we referred to intracytoplasmic globules which appeared to have arisen from Golgi complexes and passed to the plasma membrane to $\frac{x}{0}$ discharge their contents on to the cell surface and 3 into the surrounding matrix. Our previous studies $\delta$ showed that the prominent pericellular halos and lakes were composed of acid mucopolysac-? charides (Heath, 1968). Symbas, Galambos, and Sybers (1972) used the technique of Scott and Dorling (1965) to investigate the nature of these acidic mucins. They carried out differential stain-o ing of these substances in atrial thrombi in dogs $N$ and in human atrial myxomas by alcian blue in salt solutions. Despite using the anionic-site 0 blocker cetyl pyridinium chloride in the fixative, they obtained staining reactions with alcian blue $\frac{\mathscr{D}}{\mathbb{D}}$ in graded strengths of magnesium chloride which $\stackrel{\oplus}{+}$ indicated hyaluronic acid and chondroitin sul- 0 phates. Symbas et al. (1972) and Glasser et al.

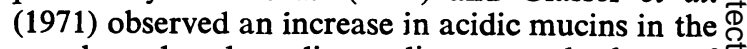
vessels and endocardium adjacent to the base of $\overrightarrow{\mathbb{Q}}$ the myxoma. A similar feature was observed $\varrho$ especially in the walls of prominent thick-walled blood vessels in the atrial septal myocardium. o These observations on the histochemistry of the 
myxoma suggest that it cannot be differentiated clearly from that of an organizing thrombus. Earlier in this discussion it was pointed out that cells of ultrastructure very similar to, if not identical with, that of the cardiac myxoma are to be found in the depths of an organizing thrombus and in contracting granulation tissue. It is clear that the classical controversy of deciding whether the cardiac myxoma is a neoplasm or thrombosis is unlikely to be resolved by histochemistry or electron microscopy.

We wish to thank Dr. H. A. Fleming for allowing us to quote clinical details of his patient. The histochemical studies were supported by a research grant made to one of us (P.G.I.S.) by the East Anglian Regional Hospital Board.

\section{REFERENCES}

Becker, C. G., and Murphy, G. E. (1969). Demonstration of contractile protein in endothelium and cells of the heart valves, endocardium, intima, arteriosclerotic plaques, and Aschoff bodies of rheumatic heart disease. Amer. J. Path., 55, 1.

Davies, M. J., Ballantine, S. J., Robertson, W. B., and Woolf, N. (1972). An ultrastructural study of experimentally induced thrombi in pig aorta. Synopsis of Paper. 125th meeting of Pathological Society of Great Britain and Ireland. Leeds. J. Path., 107, Pvi.

Disbrey, B. D., and Rack, J. H. (1970). Histological Laboratory Methods. Livingstone, Edinburgh and London.

Gabbiani, G., Hirschel, B. J., Ryan, G. B., Statkov, P. R., and Majno, G. (1972). Granulation tissue as a contractile organ. A study of structure and function. J. exp. Med., 135, 719.

Glasser, S. P., Bedynek, J. L., Hall, R. J., Hopeman, A. R., Treasure, R. L., McAllister, H. A., Esterly, J. A., Manion, W. C., and Sanford, H. S. (1971). Left atrial myxoma. Report of a case including hemodynamic, surgical, histologic and histochemical characteristics. Amer. J. Med., 50, 113.
Goodwin, J. F., Kay, J. M., and Heath, D."(1965). Myxoma of the left atrium with multiple systemic emboli. Amer. Heart J., 70, 239.

Harris, M. (1971). Ultrastructure of a glomus tumour. J. clin. Path., 24, 520.

Heath, D. (1968). Pathology of cardiac tumors. Amer. J. Cardiol., 21, 315.

- Best, P. V., and Davis, B. T. (1961). Papilliferous tumours of the heart valves. Brit. Heart J., 23, 20.

— and Mackinnon, J. (1964). Pulmonary hypertension due to myxoma of the right atrium, with special reference to the behaviour of emboli of myxoma in the lung. Amer. Heart J., 68, 227.

— and Thompson, I. M. (1967). Papilliferous "tumours" of the left ventricle. Brit. Heart J. 29, 950.

Kelly, M., and Bhagwat, A. G. (1972). Ultrastructural features of a recurrent endothelial myxoma of the left atrium. Arch. Path., 93, 219.

Merkow, L. P., Kooros, M. A., Magovern, G., Hayeslip, D. W., Weikers, N. J., Pardo, M., and Fisher, D. L. (1969). Ultrastructure of a cardiac myxoma. Arch. Path., 88, 390 .

Parry, E. W. (1970). Some electron microscope observations on the mesenchymal structures of full-term umbilical cord. J. Anat., 107, 505.

Pomerance, A. (1961). Papillary "tumours" of the heart valves. J. Path. Bact., 81, 135.

Rhodin, J. A. G. (1962). Fine structure of vascular walls in mammals; with special reference to smooth muscle component. Physiol. Rev., 42, Suppl. No. 5, 48.

Scott, J. E., and Dorling, J. (1965). Differential staining of acid glycosaminoglycans (mucopolysaccharides) by alcian blue in salt solutions. Histochemie, 5, 221.

- (1969). Periodate oxidation of acid polysaccharides. Histochemie, 19, 295.

Stein, A. A., Mauro, J., Thibodeau, L., and Alley, R. (1969). The histogenesis of cardiac myxomas: relation to other proliferative diseases of subendothelial vasoformative reserve cells. In Pathology Annual edited by S. C. Sommers, vol. 4, p. 293. Butterworths, London.

Symbas, P. N., Galambos, J. T., and Sybers, R. G. (1972). Experimental left atrial thrombus and human atrial myxoma. J. Surg. Res., 12, 8.

Todd, A. S. (1959). The histological localisation of fibrinolysin activator. J. Path. Bact., 78, 281.

Williams, W. Jones, Jenkins, D., and Erasmus, D. (1970). The ultrastructure of cardiac myxoma. Thorax, 25, 756. 